\title{
Severe winter haze days in the Beijing-Tianjin-Hebei region from 1985-2017 and the roles of anthropogenic emissions and meteorological parameters
}

5 Ruijun Dang ${ }^{1,2}$, Hong Liao $^{3 *}$

${ }^{1}$ State Key Laboratory of Atmospheric Boundary Layer Physics and Atmospheric Chemistry (LAPC), Institute of Atmospheric Physics, Chinese Academy of Sciences, Beijing, 10029, China

${ }^{2}$ University of Chinese Academy of Sciences, Beijing, 10049, China

${ }^{3}$ Collaborative Innovation Center of Atmospheric Environment and Equipment Technology/Joint International Research

10 Laboratory of Climate and Environment Change, School of Environmental Science and Engineering, Nanjing University of Information Science and Technology, Nanjing, 210044, China

Correspondence to: Hong Liao (hongliao@nuist.edu.cn) 


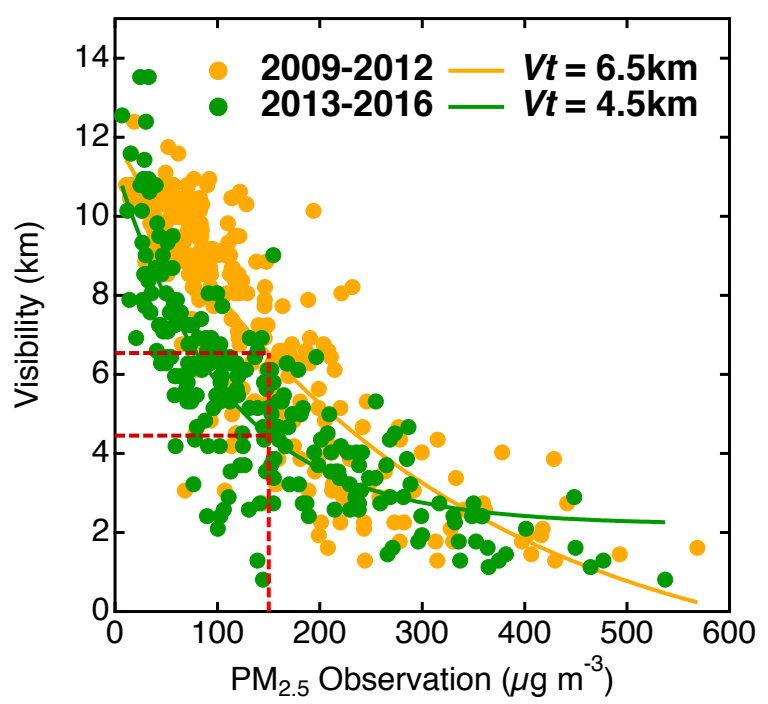

Figure S1. Approach for obtaining the visibility threshold $(V t, \mathrm{~km})$ at the Beijing site for defining SWHD based on atmospheric visibility. 1) Select the period with observations of both $\mathrm{PM}_{2.5}$ (from U.S. embassy) and atmospheric visibility (from NCDC database) available at the Beijing site: 2009-2016; 2) scatterplot the daily atmospheric visibility vs. daily mean $\mathrm{PM}_{2.5}$ for all samples over the manual period of 5 2009-2012 (yellow) and the automatic period of 2013-2016 (green); 3) for each period, perform an exponential fit as $V i s=C_{1}+C_{2}$ exp $\left(C_{3} * P M_{2.5 \_o b s}\right)$, where $\mathrm{C}_{1}, \mathrm{C}_{2}$ and $\mathrm{C}_{3}$ are all parameters, and obtain the $V t$ that corresponds to the observed $\mathrm{PM}_{2.5}$ concentration of $150 \mu \mathrm{g}$ $\mathrm{m}^{-3}$. Also presented here are the $V t$ values. The $V t$ values obtained from the 2009-2012 period were used to obtain the SWHDs for the entire manually observed period of 1985-2012, and the $V t$ values obtained from the 2013-2016 period were used for the automatically observed period of 2013-2017. 


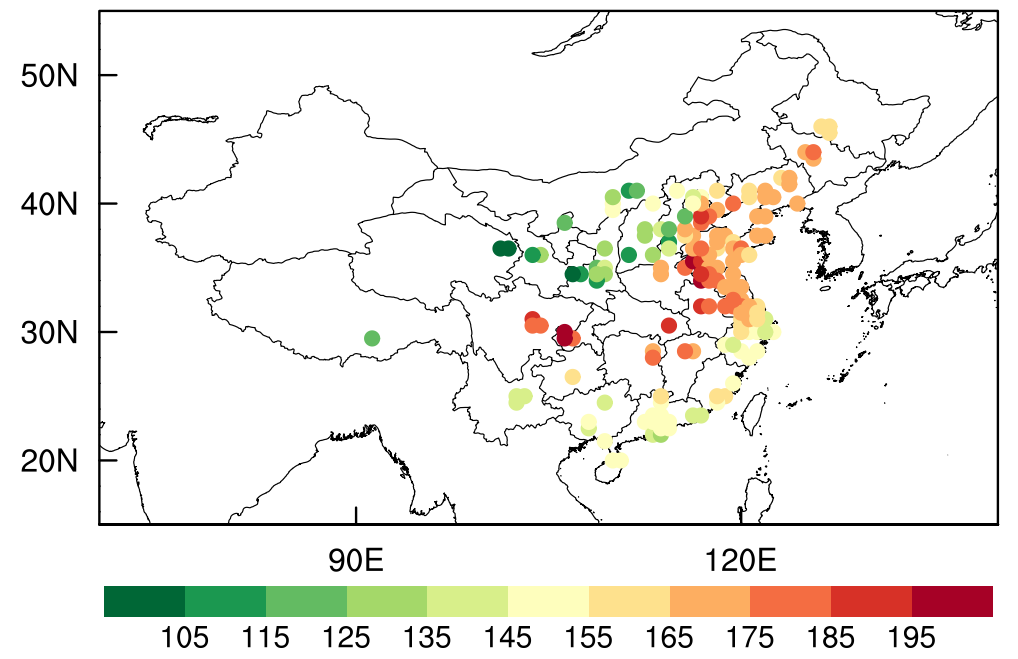

Figure S2. Obtained threshold concentrations $\left(C t, \mu \mathrm{g} \mathrm{m}^{-3}\right)$ for simulated $\mathrm{PM}_{2.5}$ at 161 grids in China. Red/green circles indicate grids with high/low biases in simulated $\mathrm{PM}_{2.5}$. The $C t$ values are used to obtain the SWHDs at each of the grids from 1985-2017. 


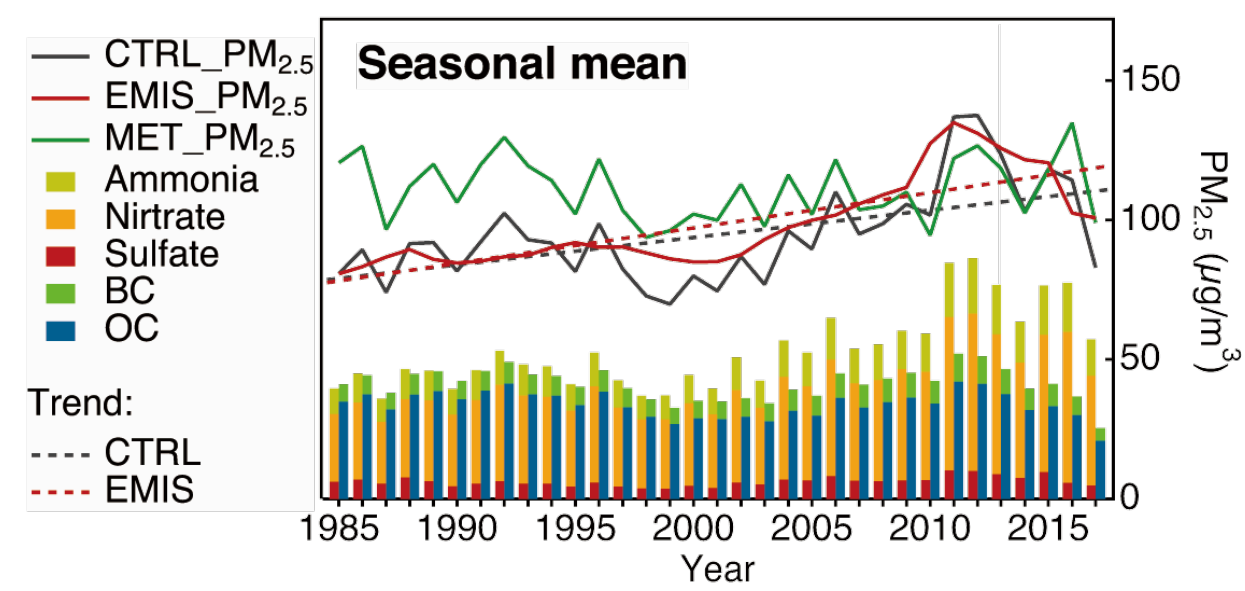

Figure S3. Time series of simulated seasonal mean concentrations of $\mathrm{PM}_{2.5}$ ( $\mu \mathrm{g} \mathrm{m}^{-3}$, CTRL: black line, EMIS: red line, MET: green line) and its components $\left(\mu \mathrm{g} \mathrm{m}^{-3}\right.$, bars) in BTH from 1985-2017. Also shown are the linear trends (dashed lines) calculated for the results of the CTRL and EMIS simulations, which are statistically significant above the $95 \%$ confidence level. The MET simulation results do not pass 5 the significance test. 